\title{
The impact of renal growth, regression and regrowth in experimental diabetes mellitus on number and size of proximal and distal tubular cells in the rat kidney
}

\author{
J.R.Nyengaard ${ }^{1}$, A. Flywbjerg ${ }^{2}$, R. Rasch ${ }^{3}$ \\ ${ }^{1}$ Stereological Research Laboratory, Aarhus University, Aarhus, Denmark \\ ${ }^{2}$ Institute of Experimental Clinical Research and Department of Medicine, Aarhus Kommunehospital, Aarhus, Denmark \\ ${ }^{3}$ Department of Cell Biology, Institute of Anatomy, University of Aarhus, Aarhus, Denmark
}

\begin{abstract}
Summary. Diabetic renal growth, regression and regrowth was studied using stereological methods on perfusion-fixed rat kidneys. The study lasted 13 weeks and comprised one control group and three diabetic groups. The first diabetic group was hyperglycaemic for 13 weeks. The second group was hyperglycaemic for 10 weeks and then normoglycaemic for 3 weeks. The third group was similar to the second group except that during the last week the animals were again hyperglycaemic. Using an optical disector on the plastic-embedded kidney slices, the number and size of proximal and distal tubular cells were estimated. The number of proximal and distal tubular cells increased by $37 \%$ and $36 \%$ during 13 weeks of experimental diabetes and the mean volume of the proximal tubular cells increased by $12 \%$ whereas the $16 \%$ increase in mean tubular cell volume was only borderline significant as compared to the control group. Normoglycaemia for 3 weeks
\end{abstract}

normalized the mean volume of distal tubular cells but the proximal tubular cells tended to be $7 \%$ smaller than those in control rats. The number of proximal cells remained increased by $21 \%$ compared with the control rats and the number of distal tubular cells retained a $17 \%$ insignificant increase. After regrowth the volume of proximal tubular cells was $20 \%$ greater than in the second diabetic group and the other parameters were unchanged. In conclusion, 13 weeks of experimental diabetes induced formation of $36 \%$ more tubular cells that were enlarged only by about $14 \%$. Normoglycaemia for 3 weeks failed to normalize the cell number. Repeated hyperglycaemia for 1 week after 2 weeks of normoglycaemia increased the size of the proximal tubular cells.

Key words: Distal tubules, experimental diabetes mellitus, insulin, kidney, proximal tubules, rats, stereology.
The kidney volume increases in human diabetes mellitus [1] and experimental diabetes [2]. The process of renal growth in experimental diabetes has been extensively studied by Seyer-Hansen [3-8] and it has been shown that the kidney growth rate exhibits two distinct phases: an initial rapid rate of growth during the first 5-7 days after induction of diabetes, and then a much slower rate which continues over several weeks.

The initial diabetic kidney growth is due to both cellular hypertrophy and hyperplasia. The first sign of growth is an increase in total RNA as early as $24-36 \mathrm{~h}$ after the onset of glycosuria $[3,8,9]$ and at about the same time the cellular pools of RNA precursors and the incorporation of orotate into uridine triphosphate are increased [10]. Shortly thereafter, an increased protein/DNA ratio is seen, indicating cellular hypertrophy. An increase in total kidney DNA is detectable only after a diabetes duration of 7 days $[3,8,9]$. However, by means of thymidine incorporation hyperplasia can be demonstrated within $48 \mathrm{~h}$ after induction of diabetes, primarily in the proximal and distal tubules [11]. In order to provide more direct evidence about the cellular reactions in diabetic renal growth and diabetic renal regression due to intensive insulin administration, the aim of this report was to estimate the number and size of proximal and distal tubular cells in diabetic renal growth, regression and regrowth using design-based stereological methods.

\section{Materials and methods}

\section{Animals}

Female Wistar rats (Møllegaards Avlslab., Eiby, Denmark) with a mean body weight of $128 \mathrm{~g}$ were studied. The rats were housed two per cage in a room with a $12: 12 \mathrm{~h}$ artificial light cycle, a temperature of $21 \pm 2{ }^{\circ} \mathrm{C}$ and at humidity $55 \pm 2 \%$. The animals had free access to standard rat chow (Altromin, Lage, Germany) and tap water throughout the experiment. Figure 1 shows the experimental design which included four groups of animals with six animals in each group. The duration of the experiment was 13 weeks. During this period one group consisted of control rats $(C)$. The first group of diabetic animals had hyperglycaemia throughout the experiment (D-H). The second group was diabetic with hyperglycaemia for the 
Table 1. Blood glucose concentration and body weight in the experimental groups studied for 13 weeks

\begin{tabular}{lllll}
\hline $\begin{array}{l}\text { Time } \\
\text { (weeks) }\end{array}$ & $\mathrm{C}$ & $\mathrm{D}-\mathrm{H}$ & $\mathrm{D}-\mathrm{HN}$ & $\mathrm{D}-\mathrm{HNH}$ \\
& & & \\
\hline $\begin{array}{lllll}\text { Blood glucose (mmol/l) } \\
0\end{array}$ & $6.66 \pm 0.69$ & $6.08 \pm 0.72$ & $6.32 \pm 0.64$ & $6.06 \pm 0.52$ \\
$1-10$ & $6.08 \pm 0.72$ & $17.4 \pm 0.98^{\mathrm{a}}$ & $17.9 \pm 1.48^{\mathrm{a}}$ & $16.9 \pm 1.83$ \\
$11-12$ & $6.10 \pm 0.57$ & $17.7 \pm 1.24^{\mathrm{a}} \mathrm{b}$ & $7.01 \pm 0.87$ & $7.62 \pm 0.84$ \\
13 & $6.54 \pm 0.60$ & $18.3 \pm 1.28^{\mathrm{a}}$ & $6.81 \pm 0.77^{\mathrm{b}}$ & $17.2 \pm 1.16$ \\
Body weight (g) & & & \\
0 & $128 \pm 4$ & $125 \pm 5$ & $131 \pm 4$ & $125 \pm 5$ \\
10 & $245 \pm 16$ & $213 \pm 15^{\mathrm{a}}$ & $218 \pm 12^{\mathrm{a}}$ & $216 \pm 10$ \\
12 & $261 \pm 20$ & $219 \pm 13^{\mathrm{a}, \mathrm{b}}$ & $255 \pm 6$ & $253 \pm 12$ \\
13 & $261 \pm 20$ & $224 \pm 13^{\mathrm{a}}$ & $264 \pm 13^{\mathrm{b}}$ & $227 \pm 6$ \\
\hline
\end{tabular}

Values given as mean $\pm 1 \mathrm{SD}$.

a $p<0.05 \mathrm{D}-\mathrm{H}$ or D-HN compared with $\mathrm{C}$;

b $p<0.05$ D-H or D-HN compared with D-HNH.

Upper panel: the mean value of blood glucose concentration in the normal control rats $(\mathrm{C})$ and in the diabetic rats. All three diabetic groups were first hyperglycaemic for 10 weeks with a blood glucose concentration of $\sim 17 \mathrm{mmol} / \mathrm{l}$. The $\mathrm{D}-\mathrm{H}$ diabetic group continued to be hyperglycaemic. The two other diabetic groups $\mathrm{D}-\mathrm{HN}$ and $\mathrm{D}$ $\mathrm{HNH}$ had normal blood glucose of $\sim 7 \mathrm{mmol} / \mathrm{l}$ for 2 weeks. During the last week of the experiment, D-HN was kept normoglycaemic while the other diabetic group $\mathrm{D}-\mathrm{HNH}$ was again made hyperglycaemic.

Lower panel: all the animals had the same mean body weight (BW $\sim 128 \mathrm{~g}$ ) when diabetes was induced. Throughout the experimental period the $\mathrm{D}-\mathrm{H}$ group had a lower body weight than the control rats, about $15 \%$. In the two groups where blood glucose was normalized, D-HN and D-HNH, the body weight was already normalized within 2 weeks and remained normalized in the D-HN group during the last week. Finally, in the D-HNH group the body weight fell again during the last week of hyperglycaemia

first 10 weeks and thereafter normoglycaemic for 3 weeks (D-HN). The third diabetic group was hyperglycaemic for the first 10 weeks, then normoglycaemic for 2 weeks and during the last week hyperglycaemic again (D-HNH).

The induction of diabetes was performed by a single i- $p$. injection of streptozotocin (STZ) (Upjohn Inc., Kalamazoo, Mich., USA) at $90 \mathrm{mg} / \mathrm{kg}$ body weight. Two days after administration of STZ, and daily thereafter, urinalysis was performed for glucose and ketones using Diastix and Ketostix (Ames Ltd, Slough, UK). Tail-vein blood glucose was determined daily in the normoglycaemic animals and weekly in the hyperglycaemic animals using a BG-test-BG (Boeringer-Mannheim, Mannheim, Germany) and Hypocount $B$ reflectance meter (Hypoguard Ltd., Woodbridge, UK). On the second day after STZ injection, when the blood glucose values were above $19 \mathrm{mmol} / \mathrm{h}$, insulin treatment with a very long-acting, heat-treated Ultralente insulin (Novo-Nordisk, Bagsværd, Denmark) [12] was initiated in all animals to induce a moderate degree of diabetes with a mean blood glucose level of about $15-20 \mathrm{mmol} / /$. Insulin was given in an initial dose of 4 IU, followed by less than 1 IU daily during hyperglycaemia and 2-4 IU daily during normoglycaemia depending on blood glucose values. The blood glucose concentration and body weight of the animals are shown in Table 1.

\section{Kidney fixation and preparation}

After 13 weeks all animals were anaesthetized with i-p. pentobarbital $(50 \mathrm{mg} / \mathrm{kg})$ and the right kidneys were perfusion-fixed retrogradely through the aorta according to Maunsbach [13]. The perfusion lasted for $5 \mathrm{~min}$ with a constant pressure of $18.7 \mathrm{kPa}$ and the perfused solution contained $4 \%$ paraformaldehyde buffered in phosphate. The weight of the perfused kidneys were then measured after which the kidneys were coded in order to evaluate them without prior knowledge of experimental grouping.

A razor blade tissue slicer [14] was used for cutting the entire kidney into 2-mm-thick slices. Every second slice was sampled systematically random. Every sampled slice from each kidney was embedded in a single capsule using glycolmethacrylate (Historesin; Cambridge Instruments, Cambridge, UK). From every plastic block one $35-\mu \mathrm{m}$-thick section and one $2-\mu \mathrm{m}$-thick section were cut using a LKB Historange microtome (Cambridge Instruments) with a glass knife. All sections were stained with periodic acid-Schiff which was modified for the thicker sections by keeping them in Mayer's haemalum for $5 \mathrm{~h}$.

\section{Volume of rat kidney cortex and tubules}

The volume of cortex, V(cortex), was estimated without bias using the Cavalieri principle [15] which is independent of the shape or the orientation of the specimen under study:

$V($ cortex $)=f \cdot t \cdot a(p) \cdot \sum P($ cortex $)$

$f$ was the sampling fraction of the kidney slices $(f=2)$, $t$ was the mean thickness of the kidney slices $(2 \mathrm{~mm})$, and a(p) was the area associated to each point used for point-counting $\left(1.14 \mathrm{~mm}^{2}\right)$. The total number of points, $\sum \mathbf{P}$ (cortex), hitting cortex, defined as the volume of the kidney superficial to the arcuate arteries [16], on the thin sections was estimated using an Olympus BHS projection microscope (see Fig. 1 in [17]) at a magnification of $\times 17$. The total volume of the proximal and distal tubules per kidney cortex was consequently estimated by point-counting on the thin sections as:

$\mathrm{V}($ tub $)=\mathrm{V}($ cortex $) \quad \frac{\sum \mathrm{P}(\text { tub })}{\sum \mathrm{P}(\text { cor })}$

where $\Sigma P(t u b)$ is the number of points hitting inside the basement membranes of either proximal or distal tubules and $\sum P($ cor $)$ the points hitting kidney cortex. The above-mentioned projection microscope, equipped with a stepping motor which moved the stageboard meander-like in kidney cortex, was used at a magnification of $\times 332$. The aim was to count about 100 points per area.

\section{Number of tubular cells}

An estimate of total number, N(total), of proximal or distal tubular cells in cortex of a rat kidney can be performed without bias using the disector-principle [18]:

$\mathrm{N}($ total $)=\mathrm{N}_{\mathrm{V}} \cdot \mathrm{V}($ tub $)$

Experimental design

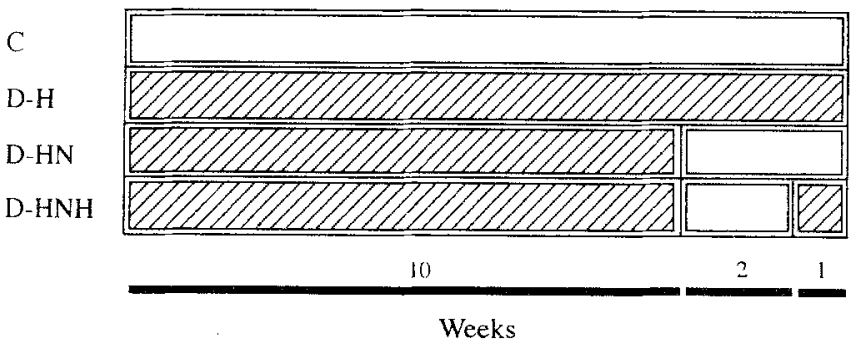

Fig. 1. The experimental design included four groups of animals: 13week-control animals (C); 13-week-hyperglycaemic animals (D-H); 10-week-hyperglycaemic, 3-week-normoglycaemic animals (D$\mathrm{HN}$ ); and diabetic animals with hyperglycaemia for 10 weeks followed by 2 weeks of normoglycaemia and 1 week of hyperglycaemia (D-HNH). The white bars indicate periods of normoglycaemia and the hatched bars indicate periods of diabetic hyperglycaemia 

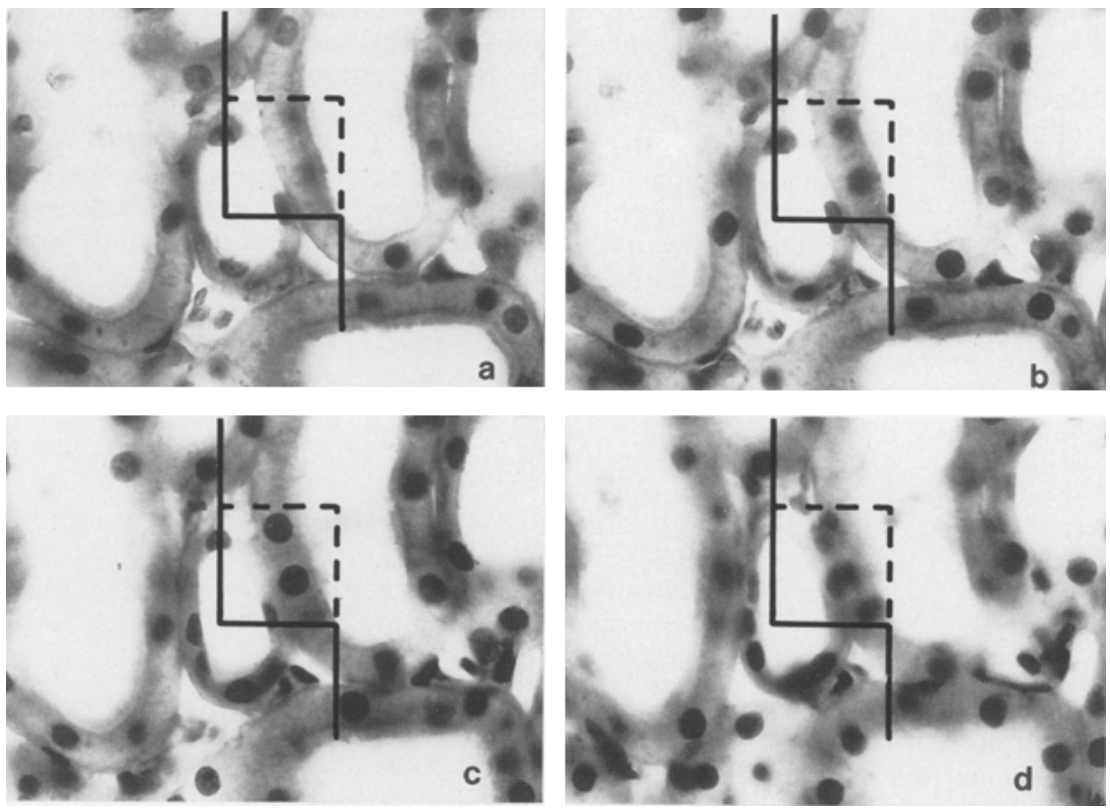

Fig. 2 a-d. Four optical sections $2 \mu \mathrm{m}$ apart in the middle of a modified periodic acid-Schiffstained glycolmethacrylate section of $35-\mu \mathrm{m}$ thickness, are shown. The full drawn lines and the dotted lines indicate the area of the twodimensional, unbiased counting frame [20]. All nuclear profiles with anything inside the counting frame, provided they do not touch or intersect the full drawn exclusion lines, are considered for counting. The observer focuses through a distance of $20 \mu \mathrm{m}$ counting any proximal or distal tubular cell nuclei coming into focus, excluding those in the first optical section and including those in the last optical section. Nuclei are counted when they are clearly in focus in the disector counting frame as is the case for the two proximal tubular cell nuclei shown in c. The bar indicates $10 \mu \mathrm{m}$
$\mathrm{N}_{v}$ denotes numerical density of tubular cells in tubules and was estimated using optical disectors [19]: the thick sections were displayed on a Sony Trinitron television screen by the use of an Olympus BHS microscope equipped with a Sony CCD color video camera (Bico A/S, Glostrup, Denmark). The video camera was interfaced through a Commodore Amiga 2000 computer loaded with software (GRID, Interactivision, Silkeborg, Denmark) superimposing a counting frame on the video images. This two-dimensional, unbiased counting frame [20] had an area, a(frame) of $713 \mu \mathrm{m}^{2}$ and presented four points $(p=4)$ on the screen. The stageboard was moved a predetermined distance in the $x, y$ direction, by means of two programmable stepping motors controlled by the grid software, to ensure a uniform sampling of cortex. Approximately 40 and 80 fields of vision were sampled per kidney for counting of proximal and distal tubular cells, respectively, because there is a greater number of proximal tubular cells than distal tubular cells in a rat kidney cortex. For each sampled counting field of the $35-\mu \mathrm{m}$-thick sections, all nuclei of proximal or distal tubular cells coming into focus and belonging to the counting frame were counted, $\Sigma \mathrm{Q}^{-}$, while the focus plane was lowered $20 \mu \mathrm{m}$ (h) down into the section (Fig. 2). The focus in the starting plane was a few $\mu \mathrm{m}$ below the surface of the section and nuclei in focus in the starting plane were not counted. A Heidenhain MT-2 microcator was mounted on the microscope to measure the distance $h$ of the stageboard. The total magnification was $\times 2,225$ using a $\times 100, N$. A . 1.40 , oil-immersion objective with a depth of focus of less than $1 \mu \mathrm{m}$. The numerical density of tubular cells was calculated as:

$\mathrm{N}_{\mathrm{V}}=\frac{\Sigma \mathrm{Q}^{-} \cdot \mathrm{p}}{\sum \mathrm{P} \cdot \mathrm{a}(\text { frame }) \cdot \mathrm{h}}$

where $\Sigma \mathrm{P}$ was the total number of points in the counting frame hitting inside the basement membrane of either the proximal or distal tubules. The proximal tubules were generally recognized by their brush border and cells having an eosinophil cytoplasm and a rounded, centrally situated nucleus. The distal tubules had no brush border, the cytoplasm was more acidophilic and in some segments the nucleus was located towards the cell apex. With the medullary rays included in our definition of cortex the collecting ducts in cortex were considered as distal tubules.

\section{Mean tubular cell volume}

The mean volume of a tubular cell, $\bar{v}(t u b)$, including the basement membrane and the lumen of the tubule was calculated as: $\bar{v}($ tub $)=\frac{V(\text { tub })}{N(\text { total })}$

e.g. the mean volume of a proximal tubular cell including lumen was the total volume of proximal tubules in cortex divided by the total number of proximal tubular cells. The mean volume of a tubular cell excluding lumen, $\overline{\mathrm{v}}(\mathrm{tub}$ cell $)$, was estimated by simple point-counting using the above-mentioned computer-controlled video microscope at a magnification of $\times 2225$ :

$\bar{v}($ tub cell $)=\bar{v}($ tub $) \frac{\sum P(\text { cell })}{\sum P(\text { cell }+ \text { lumen })}$

where $\Sigma P($ cell + lumen $)$ was number of points hitting the proximal or distal tubules within the basement membrane and $\sum \mathrm{P}$ (cell) the number of points hitting the same tubules within the basement membrane excluding the lumen. It should be mentioned that the brush border of the proximal tubule was not regarded as belonging to the proximal tubular cell.

\section{Statistical analysis}

An analysis of variances of the stereological estimators equal to the coefficient of error, $\mathrm{CE}_{\mathrm{ste}}=\mathrm{SEM} / \mathrm{mean}$, was performed on the level of blocks [21]. The coefficient of error of the Cavalieri estimator was estimated by equation 6 as reported by Gundersen and Jensen [15]. $C E_{\text {ste }}$ of the point-counting and the optical disector was estimated using equation 9 as reported by Kroustrup and Gundersen [22]. The variation of the stereological estimators can be expressed in relation to the total variation or coefficient of variation of the above-mentioned estimates, $\mathrm{CV}_{\text {tot }}=\mathrm{SD} /$ mean, where $\mathrm{CV}_{\text {bio }}$ expresses the true biological variation between animals: $\mathrm{CV}_{\text {tot }}^{2}=\mathrm{CV}_{\text {bio }}^{2}+\mathrm{CE}_{\text {ste }}^{2}$.

To reduce potential type 1 errors related to multiple comparisons, overall group differences for each parameter were first assessed by the Van der Waerden test. This was followed by individual pair-wise group comparisons (by least square means after non-parametric Blom transformation of all data) if the Van der Waerden test was significant at $p$ less than 0.05 for a given parameter. To ensure overall protection level only probabilities associated with preplanned comparisons were tested, i. e. C rats were tested against D$\mathrm{H}$ and D-HN rats, and D-HNH rats were tested against D-H and DHN rats. 


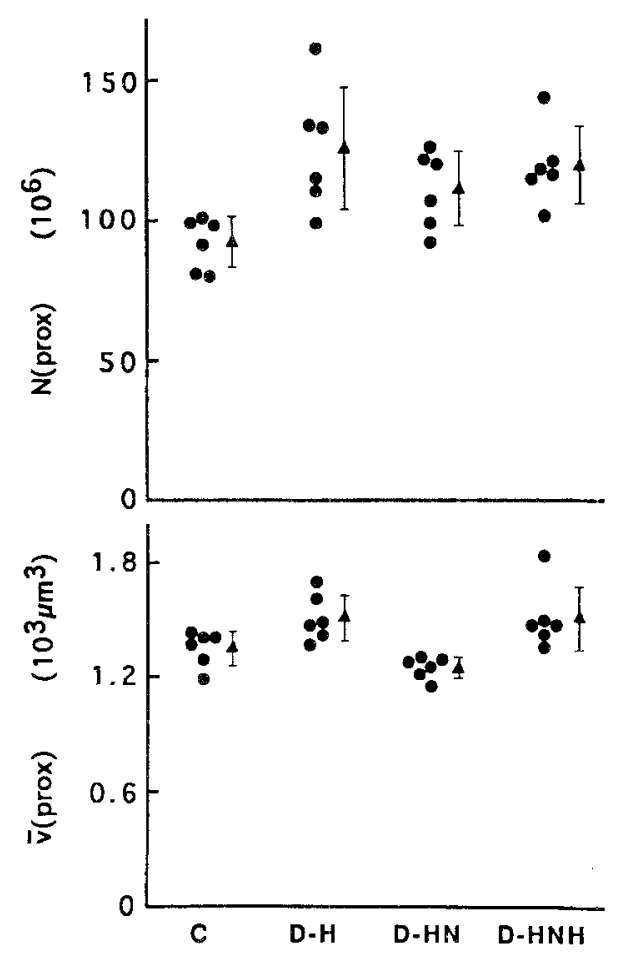

Fig.3. The number of proximal tubular cells ( $\mathrm{N}(\mathrm{prox}))$ and mean volume of proximal tubular cells ( $\overline{\mathrm{V}}(\mathrm{prox})$ ) are shown for the control rats $(\mathrm{C})$, the 13week-hyperglycaemic diabetic rats (D-H), the 10-week-hyperglycaemic, 3week-normoglycaemic rats (D-HN); and diabetic rats with hyperglycaemia for 10 weeks followed by 2 weeks of normoglycaemia and 1 week of hyperglycaemia (D-HNH). Mean and SD are shown by a triangle and bar, respectively

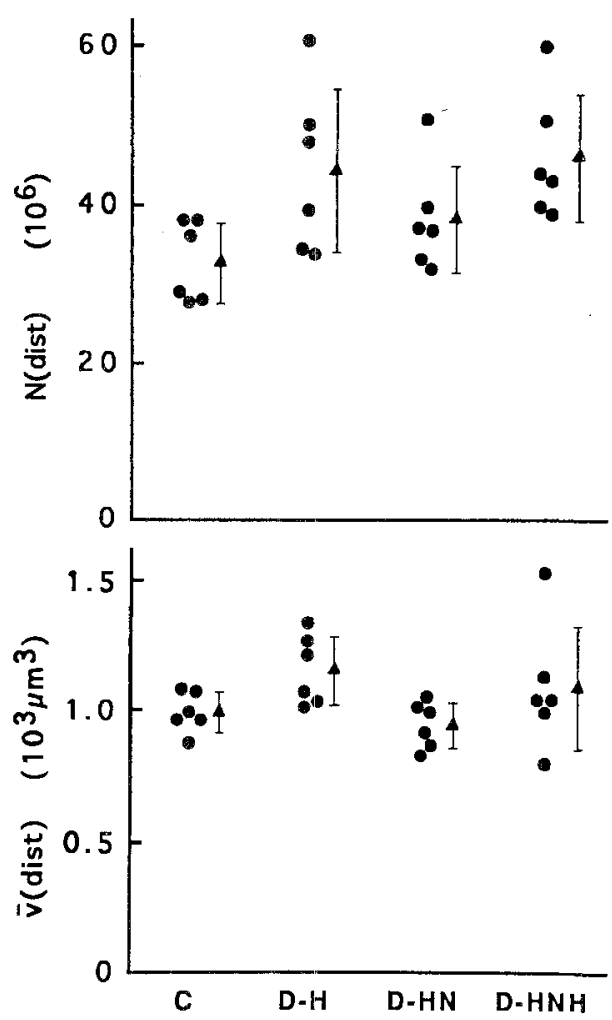

Fig.4. The number of distal tubular cells ( $\mathrm{N}(\mathrm{dist})$ ) and mean volume of distal tubular cells ( $\bar{v}(\mathrm{dist}))$ are shown for the control rats $(\mathrm{C})$, the 13-week-hyperglycaemic diabetic rats $(\mathrm{D}-\mathrm{H})$, the 10-week-hyperglycaemic, 3-week-normoglycaemic animals (D-HN); and diabetic rats with hyperglycaemia for 10 weeks followed by 2 weeks of normoglycaemia and 1 week of hyperglycaemia (D-HNH). Mean and SD are shown by a triangle and bar, respectively
Table 2. The coefficient of error $\left(\mathrm{CE}_{\mathrm{ste}}\right)$ and coefficient of variation $\left(\mathrm{CV}_{\mathrm{tot}}\right)$ are shown for the stereological estimators of total number of proximal tubular cells ( $\mathrm{N}(\mathrm{prox}))$ total number of distal tubular cells $(\mathrm{N}($ dist $))$, mean volume of proximal tubular cells $(\bar{v}($ prox $))$ and mean volume of distal tubular cells ( $\overline{\mathrm{v}}(\mathrm{dist}))$

\begin{tabular}{lllll}
\hline & $\mathrm{N}$ (prox) & $\mathrm{N}($ dist $)$ & $\overline{\mathrm{v}}($ prox $)$ & $\overline{\mathrm{v}}$ (dist) \\
\hline $\mathrm{CE}_{\text {ste }}$ & 0.08 & 0.09 & 0.04 & 0.04 \\
$\mathrm{CV}_{\text {tot }}$ & 0.13 & 0.18 & 0.08 & 0.12 \\
\hline
\end{tabular}

\section{Results}

The estimates of $\mathrm{CV}_{\text {tot }}$ and $\mathrm{CE}_{\text {ste }}$ are shown in Table 2.

The kidney weight increased from $0.99 \pm 0.11 \mathrm{~g}$ in the $\mathrm{C}$ rats to $1.52 \pm 0.27 \mathrm{~g}$ (mean $\pm \mathrm{SD}, p<0.05$ ) in the $\mathrm{D}-\mathrm{H}$ rats, whereas there was no significant difference in kidney weight between the $\mathrm{C}$ and $\mathrm{D}-\mathrm{HN}$ rats, $1.07 \pm 0.15 \mathrm{~g}$ $(p>0.05)$. The kidney weight in the D-HNH rats, $1.43 \pm 0.12 \mathrm{~g}$ was significantly different from the $\mathrm{D}-\mathrm{HN}$ rats $(p<0.05)$, but did not differ from the D-H rats $(p>0.05)$.

The total number of proximal tubular cells, $N$ (prox) (Fig. 3), was increased from $92.0 \pm 9.510^{6}$ in the $C$ rats to $126 \pm 2210^{6}$ in the D-H rats and to $111 \pm 1310^{6}$ in the D$\mathrm{HN}$ rats $(p<0.05)$. N(prox) in the D-HNH rats, $119 \pm 14$ $10^{6}$, was not significantly different from $N($ prox $)$ in the $D$ $\mathrm{H}$ or D-HN rats $(p>0.05)$.

The mean volume of proximal tubular cells, $\bar{v}$ (prox) (Fig. 3), increased from $1.35 \pm 0.0910^{3} \mu \mathrm{m}^{3}$ in the $\mathrm{C}$ rats to $1.50 \pm 0.1210^{3} \mu \mathrm{m}^{3}$ in the D-H rats $(p<0.05)$ whereas the $\mathrm{D}-\mathrm{HN}$ rats tended to have a $7 \%$ smaller $\overline{\mathrm{v}}$ (prox), $1.25 \pm 0.0610^{3} \mu \mathrm{m}^{3}$, than the $\mathrm{C}$ rats $(p=0.088)$. The $\mathrm{D}$ HNH rats had a greater $\bar{v}$ (prox), $1.50 \pm 0.1710^{3} \mu \mathrm{m}^{3}$, than the D-HN rats $(p<0.05)$ whereas it was not significantly different from the $\mathrm{D}-\mathrm{H}$ rats $(p>0.05)$.

There was an increase in the total number of distal tubular cells, N(dist) (Fig. 4), from $32.7 \pm 5.110^{6}$ in the Crats to $44.4 \pm 10.510^{6}$ in the $\mathrm{D}-\mathrm{H}$ rats $(p<0.05)$ whereas there was no significant difference from the $\mathrm{C}$ rats to the $\mathrm{D}-\mathrm{HN}$ rats, $38.2 \pm 6.910^{6}(p=0.13)$. $\mathrm{N}$ (dist) was not significantly different between the D-HNH rats, $45.9 \pm 8.010^{6}$, and the $\mathrm{D}-\mathrm{HN}$ and $\mathrm{D}-\mathrm{H}$ rats $(p>0.05)$.

The distal tubular cells had a mean volume, $\bar{v}$ (dist) (Fig. 4), of $0.99 \pm 0.0810^{3} \mu^{3}$ in the Crats which tended to increase to $1.15 \pm 0.1310^{3} \mu \mathrm{m}^{3}$ in the D-H rats $(p=0.072)$. There was no significant difference in $\bar{v}($ dist $)$ between the $C$ and the D-HN rats, $0.94 \pm 0.0910^{3} \mu \mathrm{m}^{3}(p>0.05)$. The $\bar{v}$ (dist) of the D-HNH rats, $1.09 \pm 0.1310^{3} \mu \mathrm{m}^{3}$ was not significantly different from the D-HN and D-H rats $(p>0.05)$.

\section{Discussion}

The present study shows that the number of tubular cells increases by $33 \%$ with a much smaller enlargement of the individual cells, indicating that cellular hyperplasia plays a major role in kidney enlargement during 13 weeks of experimental diabetes. Normalization of blood glucose for 3 weeks does not seem to reduce the number of tubular cells significantly, whereas tubular cell size normalized or even tended to diminish below normal size. During a re- 
peated hyperglycaemic period the number and size of tubular cells remains about the same as during the first hyperglycaemic period, suggesting that the number of cells formed in the diabetic kidney during the initial hyperplastic period remains the same for prolonged periods. It should again be emphasized that the definition of cortex and the use of light microscopy in this report resulted in no distinction between distal tubular cells and cells from collecting ducts in the medullary rays of cortex. However, a visual comparison of the number and size of proximal and distal tubular cells indicate that they respond in the same way during diabetic kidney growth, regression and regrowth.

For this study a rather young group of rats was chosen because comparisons to Type 1 (insulin-dependent) diabetic patients can be made. It cannot be excluded that older rats do not react in exactly the same way. In uninephrectomized immature rats, the remaining kidney mainly reacts by hyperplasia as opposed to the remaining kidney in uninephrectomized nature rats [23], but this matter has not yet been investigated in diabetic rats. The changes in diabetic rat tubular cells could have also been influenced by an increased dietary protein consumption as our rats were fed ad libitum. Diabetic rats eat about $50 \%$ more compared with control rats $[24,25]$. However, our rats were fed a diet with a protein content of $18 \%$ and therefore the protein intake was low. Influences of protein intake on structural kidney changes have been seen in studies with diets containing $50 \%$ protein [25].

It has previously been shown that the final DNA content increases in the diabetic kidney after 1 week $[3,8,9]$ and that the labelling index for ${ }^{3} \mathrm{H}$-thymidine incorporation increases in the tubules of the diabetic kidney at the beginning of the disease [11]. The present study supports these findings of more tubular cells in diabetic rat kidneys and suggests that the tubular cells persist for several months.

Normalization of the blood glucose for 3 weeks did not result in a significant decrease in number of proximal tubular cells. It cannot be excluded, however, that a longer period of normoglycaemia would decrease the number of proximal tubular cells similar to the distal tubular cells which showed a decrease already after 3 weeks of normoglycaemia. Glycogen nephrosis or the Armanni-Ebstein lesion was first described in human diabetes [26] and later in experimental diabetes in rats [27]. Glycogen nephrosis occurs within the distal tubules [28] and thus about $20 \%$ of the distal tubular cells contain very few organelles and miss the basolateral infoldings of the cell membrane. The nucleus is still present and normalization of the blood glucose for 5 days [29] causes the disappearance of the glycogen almost completely; 30 days [30] of normalization causes complete disappearance. In this context it is remarkable that the distal tubule can regain its original number and size of cells as a result of degeneration of some distal tubular cells and reorganization of the structure of others.

The present study suggests that the increase in tubular length found in experimental diabetes $[6,28]$ can be explained by hyperplasia and to a lesser degree, hypertrophy of the tubular cells. It has previously been found that the increased tubule length in experimental diabetes was not normalized after 4 weeks of normoglycaemia due to pancreatic islet transplantation [30]. It was then proposed that the reason for the lack of normalization of tubule length could be due to an increased number of cells in the nephron which persist after normalization of the blood glucose. This report supports the hypothesis that diabetic kidneys continue to have a greater number of tubular cells than normal kidneys. The kidney weights in D-HN rats are statistically not significantly different from that in control rats. However, the kidney weight in diabetic rats with normoglycaemia $[30,31]$ is never completely normalized. The same holds true for humans with diabetes [32]. The lack of complete normalization of kidney weight in diabetes after normalization of blood glucose could be due to the increase in tubule length during the growth period.

The cell volume of proximal tubular cells in experimental diabetes increased relatively less than the number of cells after 13 weeks of hyperglycaemia indicating hyperplasia rather than hypertrophia. The tubular cell volume rapidly responded, however, to 3 weeks of normoglycaemia by diminishing in size. Repeated hyperglycaemia for 1 week induced hypertrophy of the already-increased population of cells. Hypertrophy, therefore, seems to be the initial response to repeated hyperglycaemia, maybe followed by hyperplasia.

Acknowledgements. We thank Dr. H.J.G. Gundersen for guidance and for critical reading and helpful comments on the manuscript. The skillful technical assistance of Ms. A. M. Funder, Ms. M. Lundorf and Ms. A.Larsen is gratefully acknowledged. The study was supported by the Danish Diabetes Association, the Danish Medical Research Council, Fonden af 17-12-1981, Fonden af 1870, Fonden til lægevidenskabens Fremme, Fru Ruth I.E. Kønig-Petersens forskningsfond, Kong Christian den Tiendes Fond, the Nordic Insulin Foundation, NOVO Foundation, Nyreforeningens Forskningsfond, and Aarhus University Research Foundation.

\section{References}

1. Mogensen CE, Andersen MJ (1973) Increased kidney size and glomerular filtration rate in early juvenile diabetes. Diabetes 22: 706-712

2. Ross J, Goldman JK (1971) Effect of streptozotocin-induced diabetes on kidney weight and compensatory hypertrophy in the rat. Endocrinology 88: 1079-1082

3. Seyer-Hansen K (1976) Renal hypertrophy in streptozotocin diabetic rats. Clin Sci Mol Med 51: 551-555

4. Seyer-Hansen K (1977) Renal hypertrophy in experimental diabetes: relation to severity of diabetes. Diabetologia 13 : 141-143

5. Seyer-Hansen K (1978) Renal hypertrophy in experimental diabetes: a comparison to compensatory hypertrophy. Diabetologia 14: $325-328$

6. Seyer-Hansen K, Hansen J, Gundersen HJG (1980) Renal hypertrophy in experimental diabetes: a morphometric study. Diabetologia 18: 501-505

7. Seyer-Hansen K, Gundersen HJG, Østerby R (1981) Acute renal hypertrophy in experimental diabetes: lack of effect of growth hormone administration. Diabetologia 21:374-376

8. Seyer-Hansen K (1983) Renal hypertrophy in experimental diabetes. Kidney Int 23: 643-646

9. Flyvbjerg A, Thorlacius-Ussing O, Næraa R, Ingerslev J, Ørskov $\mathrm{H}$ (1988) Kidney tissue somatomedin $\mathrm{C}$ and initial renal growth 
in diabetic and uninephrectomized rats. Diabetologia 31 : 310-314

10. Cortes P, Lewin NW, Dumler F, Rubinstein AH, Verghese CP, Vankatachalam KK (1980) Uridine triphosphate and RNA synthesis during diabetes-induced kidney growth. Am J Phys 238: E349-E357

11. Rasch R, Nørgaard JOR (1983) Renal enlargement: comparative autoradiographic studies of ${ }^{3} \mathrm{H}$-thymidine uptake in diabetic and uninephrectomized rats. Diabetologia 25: 280-287

12. Rasch R (1979) Control of blood glucose levels in streptozotocin diabetic rat using a long-term heat-treated insulin. Diabetologia 16: $185-190$

13. Maunsbach $\mathrm{AB}$ (1966) The influence of different fixatives and fixation methods on the ultrastructure of rat kidney proximal tubule cells. I. Comparison of different perfusion fixation methods and of glutaraldehyde, formaldehyde and osmium tetroxide fixatives. J Ultrastr Res 15:242-282

14. Baddeley AJ, Gundersen HJG, Cruz-Orive LM (1986) Estimation of surface area from vertical sections. J Microsc 142:259-276

15. Gundersen HJG, Jensen EB (1987) The efficiency of systematic sampling in stereology and its prediction. J Microsc 147: 229-263

16. Kriz W, Bankir L (1988) A standard nomenclature for structures of the kidney. Kidney Int 33: 1-7

17. Sørensen FB (1991) Stereological estimation of the mean and variance of nuclear volume from vertical sections. J Microsc 162: 203-229

18. Sterio DC (1984) The unbiased estimation of number and sizes of arbitrary particles using the disector. J Microse 134: 127-136

19. Gundersen HJG (1986) Stereology of arbitrary particles. A review of unbiased number and size estimators and the presentation of some new ones, in memory of William R. Thompson. J Micros 143: 3-45

20. Gundersen HJG (1977) Notes on the estimation of the numerical density of arbitrary profiles: the edge effect. J Microsc 111: 219-223

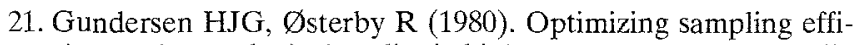
ciency of stereological studies in biology: or 'Do more less well'. J Microsc 121: 65-73

22. Kroustrup JP, Gundersen HJG (1983) Sampling problems in an heterogeneous organ: quantitation of relative and total volume of pancreatic islets by light microscopy. J Microsc 132;43-55
23. Karp R, Brasel JA, Winick M (1971) Compensatory kidney growth after uninephrectomy in adult and infant rats. Am J Dis Child 121: 186-188

24. Flyvbjerg A, Marshall SM, Frystyk J, Hansen KW, Harris AG, $\emptyset$ rskov $\mathrm{H}$ (1992) Octreotide administration in diabetic rats: effects on renal hypertrophy and urinary albumin excretion. Kidney Int 41:805-812

25. Mauer SM, Steffes MW, Azar S, Brown DM (1989) Effects of dietary protein content in streptozotocin-diabetic rats. Kidney Int 35: $48-59$

26. Armanni L (1877) Fünf Autopsien mit histologischen Untersuchungen und klinischer Epicrise in der Diabetes Melitus. In: Catani A (ed) Vierzehnte Vorlehsung. Denicks Verlag, Berlin, pp 315-329

27. Curtis GW, Robbins SL, Glickmai I (1947) Studies on glycogen nephrosis in alloxan-treated rats. J Exp Med 85:373-379

28. Rasch R (1984) Tubular lesions in streptozotocin-diabetic rats. Diabetologia 27: 32-37

29. Rasch R (1991) Growth and regression of kidneys in experimental diabetes before and after insulin treatment. A morphometric study of glomeruli, tubules and interstitium. J Am Soc Nephrol2: 296 (Abstract)

30. Rasch R, Gøtzsche O (1988) Regression of glycogen nephrosis in experimental diabetes after pancreatic islet transplantation. APMIS 96: 749-754

31. Stackhouse S, Miller PL, Park SK, Meyer TW (1990) Reversal of glomerular hyperfiltration and renal hypertrophy by blood glucose normalization in diabetic rats. Diabetes 39: 989-995

32. Wiseman MJ, Saunders AJ, Viberti GC, Keen H (1985) The effect of blood glucose control on increased glomerular filtration rate and kidney size in insulin-dependent diabetes. N Engl J Med $312: 617-620$

Received: 14 December 1992

and in revised form: 25 March 1993

Dr. J.R. Nyengaard

Stereological Research Laboratory

Bartholin Building

Aarhus University

DK-8000 Arhus C

Denmark 